\title{
Interactive comment on "Controls on the hydraulic geometry of alluvial channels: bank stability to gravitational failure, the critical-flow hypothesis, and conservation of mass and energy" by Jon D. Pelletier
}

\section{Gordon Grant (Referee)}

gordon.grant@usda.gov

Received and published: 22 July 2020

This intriguing paper suggests that the well-known downstream hydraulic geometry relations and exponents can be at least partially explained by postulating that bankfull height (hence bankfull depth) is set by the balance of forces leading to gravitational failure. Key to this mechanism is the amount of bank cohesion, which is interpreted to result from clay content. A further constraint on hydraulic geometry comes from the recognition that Froude numbers in natural channels are typically less than or nearcritical, giving rise to a relatively well-behaved relationship between Froude number 
and discharge, from which the velocity exponent (and therefore the width exponent by conservation of mass) can be calculated. An extension of this analysis allows the longitudinal slope exponent to be calculated as well. Results using this approach compare quite favorably with large published datasets in both the Mississippi basin and globally.

That said, I remain somewhat skeptical of both the approach and the results. My skepticism is rooted in both some of the underlying theory and assumptions used to derive the mathematical relations that underpin this work, and also the wide variance and assumptions in the data used to validate the methods. I cannot put my finger on a single "smoking gun" amidst all of this, but I was quite surprised that given all the assumptions and uncertainties, the predicted relationships were almost spot-on the widely published values (starting with Leopold and Maddock) for the hydraulic geometry relationships. Herein lies the intrigue, but l'm not convinced that the right answer was obtained for the right reasons. To his credit, the author acknowledges the fragility of some of the assumptions, and calls for additional work to better understand key relationships. Thus, this paper will stimulate discussion and work and deserves to be shared with the broader community, irrespective of any misgivings.

The postulated relation between bankfull height and clay content builds on previous work, but as the author points out, the assumption in this earlier work was that cohesion limited erosion by increasing the required near-bank shear stresses for fluvial entrainment. Here the focus is on gravitationally-driven stress failures, modeled with a very simple 1-D relationship (Eq. 2), that when parametrized, gives rise to an even simpler linear equation between bankfull depth and maximum gravitationally stable bank height. This relation is tested at the scale of the Mississippi River basin by comparing bankfull height derived from USGS gage station data with predicted height calculated from clay content derived for each station using gNATSGO soil survey data and estimated with a $10 \mathrm{~km}$ moving window. Not surprisingly, the resulting scatter plot is. . well, scattered with a weak positive trend (Fig. 2A). The author does synthetically consider what the error in this relationship might look like; this error analysis is not propagated

\section{ESurfD}

Interactive comment
Printer-friendly version

Discussion paper (1) 
through the rest of the analysis, however. At the end of the day, I remain skeptical that broad-scale soil survey data can be used to parametrize clay content for point data (USGS stations). To be fair, in the discussion the author does consider other sources of potential error beyond data error, including the use of stage data as a proxy for bank height, and other possible channel adjustments to varying clay content (i.e., varying bank angle, widening). But taken together, these uncertainties raise doubts about the validity of the paper's central claim that bankfull height is primarily controlled by gravitational slope failure.

While I'm appreciative of the author's invoking the "critical flow hypothesis" (correct citation is Grant, 1997, not 2000 as it appears in text but not references), I'm somewhat confused by the role it plays in this story. As I understand it, the author argues that this hypothesis suggests that the range of Froude numbers for both sand and gravel-bed channels should be limited to near- or less than 1.0, and that therefore Froude number and discharge should be weakly and inversely related. The logic here is not entirely clear, and the mechanism that restricts Froude numbers is not entirely accurate. In its original form, the hypothesis argues that in steep channels (typically $S>0.01$ ), interactions between the free surface (particularly hydraulic jumps) and the bed result in a rough balance between forces that accelerate the flow and forces that extract energy from the flow and thus retard it, thus promoting near-critical flow conditions. This condition applies irrespective of grain size, although the author rightly points out that the actual bed features that set up this interaction are different for sand, gravel, and even boulder bed channels. A recent paper tests this idea in the flume and articulates the mechanism well (Piton and Recking, 2019). Most of the streams in the Dunne and Jerolmack data set have slopes much less than 0.01 , and consequently much lower Fr, as the data shown in the paper point out.

Printer-friendly version

More to the point, in my view, the primary control on Fr is channel slope, and I suspect that this is what is behind the weak inverse correlation between Fr and discharge (Fig. 3A). The simple theoretical dependency between Fr and S is shown in Grant (1997;

Discussion paper

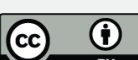


Fig. 4); a more sophisticated treatment is given in Palucis and Lamb (2017; Fig. 2). Since smaller streams tend to be steeper than larger ones, my hunch is that discharge is more of a proxy for slope than a driver as in Fig. 3A. This slope dependency is also probably lurking behind the grain-size/Fr relationship in Fig. 3B as well. None of this fundamentally invalidates the argument being made by the author but I think these relations should be acknowledged, as they have bearing on the physical mechanisms underlying the presentation.

Overall, although the tone of this review might seem negative, I think the paper is well-written and the author raises some interesting points. This work should stimulate a provocative exchange and deserves a wider audience and discussion after these technical issues are addressed.

\section{Gordon Grant}

References cited:

Grant, Gordon E. "Critical flow constrains flow hydraulics in mobileâĂŘbed streams: A new hypothesis." Water Resources Research 33.2 (1997): 349-358.

Palucis, M. C., and M. P. Lamb. "What controls channel form in steep mountain streams?." Geophysical Research Letters44.14 (2017): 7245-7255.

Piton, Guillaume, and Alain Recking. "Steep BedloadâĂŘLaden Flows: Near Critical?." Journal of Geophysical Research: Earth Surface 124.8 (2019): 2160-2175.

Interactive comment on Earth Surf. Dynam. Discuss., https://doi.org/10.5194/esurf-2020-44, 2020. 